\title{
Perancangan Taman Edukasi di Sekolah Harapan Bunda Jimbaran
}

\author{
Ferry Zulkifli Febrian Afaraby ${ }^{1}$, Lury Sevita Yusiana ${ }^{1 *}$, Ni Wayan Febriana Utami ${ }^{1}$ \\ 1. Prodi Arsitektur Lanskap, Fakultas Pertanian, Universitas Udayana, Jl. P.B. Sudirman, Denpasar, \\ Indonesia \\ *E-mail: lury.yusiana@unud.ac.id
}

\begin{abstract}
Education Garden Design In Sekolah Harapan Bunda Jimbaran. School is a place for students to learn and build their character. Meanwhile, environmental damage caused by human activities is increasing, so that environmental awareness on school need to be developed by providing educative facilities in the form of school open space. This created to fullfill comfortable school environments while providing educative facilities and build environmental awareness of students with the adiwiyata concept which is a school program aims to encourage schools to adopt behaviors that are respectful towards the environment. This research was conducted at Harapan Bunda School (HBS), Jimbaran, Bali which has a large open space area but has not been optimized. Several facilities have been damaged due to dysfunction. The study aims to design a gardenbased learning area to optimize the potential of the outdoor space and solve the problem in the HBS. Method used in this research was field survey by implementing data collection techniques such as observation, interviews, questionnaire and literature studies. The results showed that the SHB area was designed by dividing the area into three main area i.e. activity areas, functional areas and areas of space requirements. Areas of activity include active and passive areas. Whereas, functional areas include reception areas, connecting areas and main areas. According to space requirements, the area were divided into built areas, open space and green open space equipped with pergola facilities and some benchs to support passive activities and playing fields to support active activities. Hydroponic areas and vertical gardens are also provided support green open spaces.
\end{abstract}

Keywords: adiwiyata, garden-based learning, Jimbaran, schools outdoor space

\section{Pendahuluan}

Sekolah adalah bangunan atau lembaga untuk belajar serta tempat menerima dan memberi pelajaran (Daryanto dalam Widiyawati, 2018). Sekolah juga merupakan lingkungan kedua tempat anak-anak berlatih dan menumbuhkan kepribadiannya. Dalam menumbuhkan kepribadian anak di sekolah, penting untuk menghadirkan lingkungan yang mampu mengedukasi anak untuk peduli terhadap lingkungan. Taman edukasi merupakan fasilitas pendukung yang dapat diterapkan di pekarangan sekolah dan bertujuan menumbuhkan karakter peduli lingkungan, menyediakan fasilitas pendidikan dan membuat lingkungan menjadi nyaman. Salah satu sekolah yang berpotensi menerapkan taman edukasi dengan konsep adiwiyata adalah Sekolah Harapan Bunda (SHB) di Jimbaran. Potensi tersebut dikarenakan kondisi pekarangan sekolah yang luas akan tetapi belum mampu dioptimalkan. Adiwiyata adalah salah satu program Kementerian Negara Lingkungan Hidup dalam rangka mendorong terciptanya pengetahuan dan kesadaran warga sekolah dalam upaya pelestarian lingkungan hidup. Konsep ini penting bagi siswa ditengah banyaknya kerusakan lingkungan yang terjadi.

Sekolah ini terletak di Kabupaten Badung yang hanya memiliki satu sekolah dengan konsep adiwiyata. Sekolah ini memiliki siswa di tingkat PAUD (Pendidikan Anak Usia Dini) hingga SMP (Sekolah Menengah Pertama) sehingga cukup kompleks dalam jenjang pendidikan. Kompleksnya jenjang pendidikan juga menimbulkan masalah, yaitu rusaknya taman bermain anak akibat penyalahgunaan fungsi. Selain itu, fasilitas sekolah kurang memadai untuk jenjang pendidikan yang kompleks. Berdasarkan aspek kajian tersebut, perlu adanya penelitian mengenai perancangan taman edukasi yang sesuai dengan kondisi SHB. Penelitian ini bertujuan untuk merancang taman edukasi, mengoptimalkan potensi dan mengatasi kendala di SHB. Taman edukasi dibangun dalam rangka menciptakan lingkungan sekolah yang nyaman, menyediakan fasilitas pendidikan dan membangun kesadaran lingkungan siswa. 


\section{Metode}

\subsection{Waktu dan Lokasi}

Lokasi penelitian ini terletak di Sekolah Harapan Bunda Jimbaran, Kabupaten Badung, Provinsi Bali (Gambar 1). Penelitian ini dilaksanakan selama 10 bulan dimulai dari bulan Maret hingga Desember 2019.

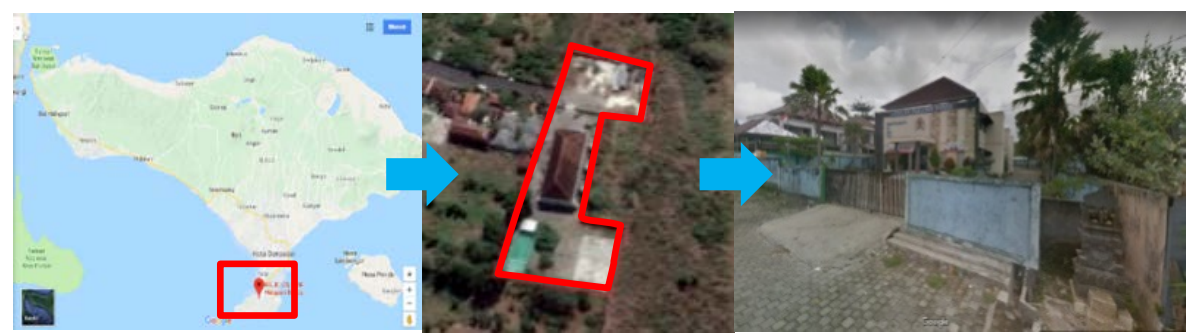

Gambar 1. Lokasi Penelitian (Google maps, 2019)

\subsection{Alat dan Bahan}

Alat dan bahan yang digunakan yaitu alat ukur berupa meteran, smartphone, Laptop dengan perangkat lunak Microsoft Word, Microsoft Excel, AutoCAD 2016, SketchUp 2016, Adobe Photoshop CS5, alat tulis dan lembar kuesioner tentang kegiatan pengguna lahan.

\subsection{Metode Penelitian}

Metode penelitian yang digunakan untuk penelitian ini adalah metode survei dengan teknik pengumpulan data melalui observasi, wawancara, penyebaran Kuesioner dan studi pustaka. Tahapan yang dilakukan didasari dari apa yang dikemukakan oleh Gold dalam Ginanjar (2008) yang meliputi tahap pengumpulan data awal, penyebaran kuesioner, inventarisasi, analisis, sintesis, perencanaan, perancangan dan site plan. Observasi dilakukan secara langsung ke lokasi penelitian untuk mengetahui kondisi fisiknya. Wawancara dilakukan kepada pengelola sekolah dan guru bertujuan untuk mengetahui informasi mengenai sekolah dan aktivitas pengguna. Penyebaran kuesioner menggunakan Purposive Sampling dengan kriteria yaitu warga sekolah yang menggunakan pekarangan sekolah dan dapat menjawab kuesioner dengan baik. Total terdapat 50 sampel terdiri dari siswa sekolah, guru, dan karyawan SHB. Siswa sekolah dipilih untuk kelas SMP dan SD kelas 5 dan 6, akan tetapi untuk siswa SD didampingi oleh guru untuk membantu menjawab kuesioner yang kurang dimengerti. Pertanyaan yang diajukan mengenai kondisi tapak, aktivitas yang dilakukan, frekuensi penggunaan tapak, tata guna lahan, aksesibilitas, fasilitas, keamanan dan kenyamanan di tapak. Batasan penelitian ini dilakukan pada pekarangan SHB yaitu bagian depan dan belakang sekolah. Penelitian ini dilakukan hingga tahap site plan yang merupakan hasil dari analisis dan sintesis kondisi tapak.

\section{Hasil dan Pembahasan}

\subsection{Gambaran Umum Lokasi Penelitian}

Sekolah Harapan Bunda (SHB) adalah salah satu sekolah yang ada di Kelurahan Jimbaran, Kecamatan Kuta Selatan, Kabupaten Badung, Provinsi Bali. Sekolah ini memiliki pekarangan seluas $30 \mathrm{~m}^{2}$ yang ada di belakang gedung sekolah. Sekolah yang dirintis sejak tahun 1997 ini semula hanya melayani sekolah Play Group dan TK (Taman Kanak-kanak). Kemudian berkembang hingga melayani PAUD (Pendidikan Anak Usia Dini), SD (Sekolah Dasar) dan SMP (Sekolah Menengah Pertama). Jumlah siswa pada tahun ajaran 2019/2020 mencapai 86 siswa dengan guru dan karyawan berjumlah 42 orang. Sekolah ini memiliki kepala sekolah di setiap jenjang pendidikan yang terdiri dari Dra. Endah Setyowati pada PAUD dan Jeanne Selvya Damorita Rotte, S.Pd, M.Pd. pada SD dan SMP yang juga merupakan Ketua Yayasan Harapan Bunda. Penunjukan kepala sekolah tidak memiliki periode tertentu karena merupakan sekolah swasta.

\subsection{Inventarisasi}

Kondisi iklim berdasarkan data BMKG tahun 2012-2016, Berdasarkan data rata-rata curah hujan dapat diketahui jika daerah ini memiliki iklim D yaitu sedang menurut klasifikasi iklim Schmidt Ferguson dengan menggunakan metode bulan basah dan bulan kering. Menurut Mursitantyo (2015), Tanah di Jimbaran 
termasuk dalam jenis tanah mediteran dan termasuk golongan batuan formasi selatan. Formasi ini memiliki karakteristik yang terdiri atas koral dan kapur. Kemudian kapur koral berkembang menjadi topografi berbukit dengan ketinggian $28 \mathrm{~m}$ dpl yang memiliki kemiringan lahan $>15$ - 30\% dan termasuk dalam kategori daerah miring. Kondisi hidrologi di area ini memiliki debit air yang hanya 1,09 It/dt berdasarkan data pada Rencana Terpadu Program Investasi Infrastruktur Jangka Menengah (RPI2JM) Kab. Badung Tahun 2014. Selain itu, sungai yang ada di jimbaran merupakan sungai periodik yang hanya berair dan terisi pada saat hujan. Kondisi air dan tanah yang berkapur membuat vegetasi di pekarangan sekolah banyak yang mati. Tanaman yang masih bisa bertahan yaitu pohon ketapang berada di tempat bermain, pohon mangga di depan kolam renang dan pohon glodokan tiang yang ada di sisi-sisi halaman.

Pekarangan di sekolah ini memiliki beberapa fasilitas yaitu lapangan basket, kolam renang, tempat bermain anak, tempat parkir, kantin dan padmasana (tempat ibadah agama Hindu). Akses menuju pekarangan belakang sekolah dapat melewati jalan sebelah gedung sekolah atau masuk ke dalam gedung sekolah. Pekarangan ini juga digunakan untuk aktivitas siswa TK yang cenderung aktif bergerak seperti berlari-larian, bermain petak umpet, bermain perosotan dan berolahraga. Aktivitas bagi siswa SD hampir sama dengan anak TK, tetapi lebih memiliki tanggung jawab dan logika yang sudah mulai berkembang. Siswa SD dan SMP lebih banyak melakukan aktivitas di kantin pada siang hari daripada melakukan aktivitas fisik seperti bermain sepak bola, basket dan berlari-lari karena pekarangan sekolah panas dan kurang tempat teduh.

\subsection{Analisis dan Sintesis}

\subsubsection{Aktivitas}

Sekolah dengan luas $30 \mathrm{~m}^{2}$ memiliki area yang belum dimanfaatkan secara optimal sehingga memiliki potensi untuk dikembangkan menjadi taman edukasi. Taman edukasi dipilih karena sekolah sebagai tempat menerima dan memberi pelajaran sehingga dapat mendukung proses belajar mengajar di sekolah. Menurut Mandagi (2013), taman edukatif merupakan sarana bagi anak sekolah untuk memiliki rasa ingin tahu yang tinggi tentang keilmuan atau sains sehingga tertarik untuk mempelajarinya. Lebih lanjut diungkapkan bahwa terdapat kriteria dalam taman edukatif, yaitu : 1) Adanya ruang edukasi, 2) Penggunaan elemen keras dan lunak, dan 3) Adanya ruang bermain.

Aktivitas yang ada di pekarangan sekolah ini banyak dilakukan saat jam olahraga dan pagi hari. Hal itu karena saat pagi hari suasana pekarangan tidak terlalu panas. Kondisi pekarangan yang panas menyebabkan siswa lebih banyak yang beraktivitas di kelas dan di kantin dibanding dengan di pekarangan sekolah. Ditambah lagi dengan kurangnya fasilitas yang ada di pekarangan sekolah untuk bersosialisasi dan bersantai. Ada banyak potensi kegiatan yang dapat dilakukan di pekarangan sekolah seperti basket, sepak bola, bermain, atau hanya duduk-duduk santai. Selain itu, sekolah ini juga memiliki kegiatan menari, melukis dan pencak silat yang merupakan aktivitas yang masuk dalam kurikulum pembelajaran. Untuk itu pekarangan sekolah memerlukan penambahan fasilitas yang dapat mendukung aktivitas siswa di pekarangan sekolah.

Adanya taman edukasi diharapkan dapat menjadi sarana edukasi dalam meningkatkan kepedulian siswa terhadap lingkungan. Salah satunya dengan adanya aktivitas berkebun, membuang sampah pada tempatnya, pengenalan jenis-jenis tanaman. Hal itu dapat meningkatkan wawasan siswa dan dapat diterapkan di rumah yang perlahan-lahan dapat merubah kebiasaan orang-orang yang ada di rumah. Selain itu, Taman edukasi dapat digunakan siswa PAUD untuk pengenalan elemen-elemen keras dan lunak, contohnya : elemen keras berupa paving dan batu-batuan, kemudian elemen lunak berupa tanaman dan kayu pada bangunan. Sedangkan bagi siswa SD dapat digunakan untuk menambah wawasan mengenai cara bertanam dan merawat tanaman. Kemudian bagi siswa SMP dapat digunakan untuk melatih tanggung jawab dengan menjaga fasilitas yang sudah disiapkan. Selain itu penambahan papan informasi sebagai sarana meningkatkan pemahaman mengenai desain taman di sekolah dan cara menjaga lingkungan yang disesuaikan dengan jenjang pendidikan.

\subsubsection{Fasilitas}

Sekolah ini memiliki jenjang pendidikan yang kompleks, sehingga perlu peningkatkan dan pembagian fasilitas sesuai masing-masing jenjang pendidikan. Penambahan fasilitas tempat duduk diperlukan untuk siswa sesuai dengan jenjang pendidikannya agar bisa bersantai saat jam istirahat. Hal itu karena saat ini kurangnya tempat duduk di pekarangan sekolah untuk beristirahat sehingga banyak siswa yang hanya di kelas dan pergi ke kantin. Selain itu lahan yang cukup luas dapat dimanfaatkan untuk penambahan pergola dan wantilan. 
Fasilitas pergola dipilih karena siswa SMP dan SD jarang beraktivitas di pekarangan sekolah karena suasananya panas. Adanya pergola dapat digunakan untuk bersantai saat istirahat dan opsi belajar diluar ruangan bagi siswa SD dan SMP. Fasilitas tersebut untuk menunjang kegiatan belajar mengajar disekolah sehingga siswa dapat memiliki pengalaman baru dan tidak bosan untuk belajar di dalam kelas. Sedangkan, fasilitas wantilan dipilih karena di sekolah ini memliki aktivitas menari, menggambar dan berlatih silat bagi siswa SD dan PAUD sehingga sengaja tidak diberi kursi. Selanjutnya, fasilitas taman bermain anak bagi siswa PAUD dibuat lebih nyaman dengan adanya pohon untuk menaunginya. Hal itu dikarenakan saat ini kurangnya pohon yang menaungi taman bermain sehingga suasana menjadi panas.

\subsubsection{Topografi}

Kondisi topografi di sekolah ini memiliki kemiringan 15\% - 30\% yang dapat membahayakan pengguna pekarangan sekolah. Salah satu cara mengatasi lahan miring dapat menggunakan metode cut and fill. Metode ini dilakukan dengan memotong area tanah yang lebih tinggi untuk digunakan menutup atau menimbun area yang rendah sehingga permukaan tanah menjadi datar. Area yang memerlukan metode ini berada di samping gedung sekolah. Area ini dibagi menjadi 3 level perbedaan dengan ketinggian $45 \mathrm{~cm}$ tiap levelnya. Bentuk topografi dapat dilihat pada Gambar 2.

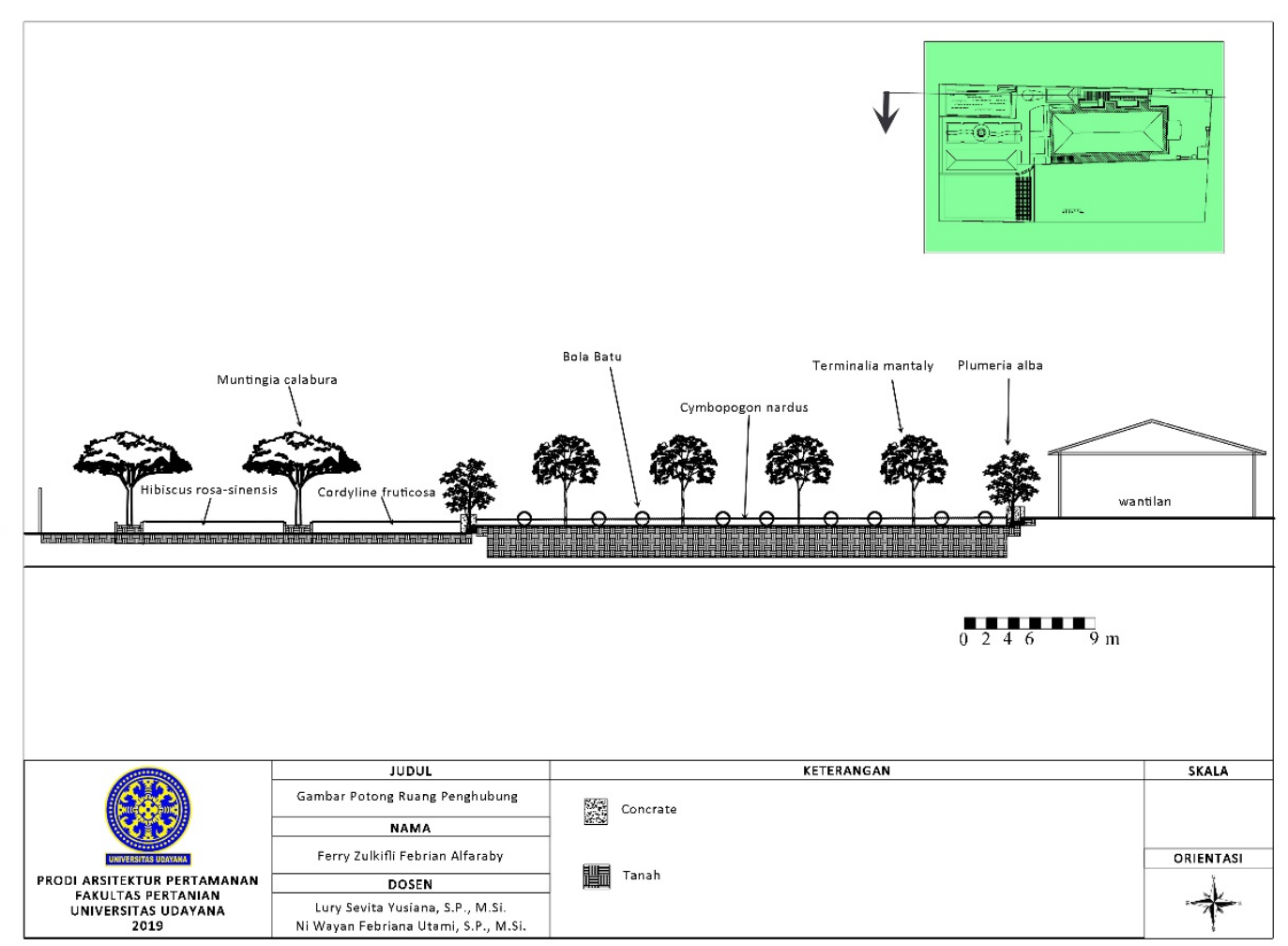

Gambar 2. Gambar Potong

\subsubsection{Air}

Kondisi tanah yang berkapur menyebabkan sulitnya mendapatkan air di SHB. Hal itu dapat diatasi dengan pembuatan fasilitas Penampung Air Hujan (PAH) sebagai cadangan air. Penggunaan PAH bagi pengguna hanya digunakan saat air PDAM bermasalah, karena penggunaan air PAH harus menggunakan perlakuan khusus dan lebih disarankan untuk pemeliharaan taman sehingga dapat mengurangi penggunaan air PDAM. Pembuatan PAH disesuaikan dengan banyaknya air yang dapat ditampung dan kebutuhan air yang diperlukan. Kebutuhan air dapat diketahui dengan menjumlahkan kebutuhan air pengguna dan kebutuhan air tanaman. Kebutuhan air untuk sektor sekolah memerlukan 10 liter per murid dalam sehari (Awwalin, 2016). Jumlah air maksimal yang dibutuhkan dalam 31 hari yaitu sebanyak 44.218 liter dengan jumlah pengguna 128 orang ditambah jumlah kebutuhan air tanaman sebanyak 150 liter per hari. Jumlah pengguna merupakan 
gabungan dari guru, karyawan dan siswa. Kemudian, banyaknya air hujan yang dapat ditampung dihitung dengan mengalikan luas atap dengan rata-rata hujan dalam satu bulan selama setahun. Luas atap yang digunakan diketahui memiliki luas $683 \mathrm{~m} 2$ dan rata-rata hujan perbulan dalam satu tahun yaitu 120.054 liter

Menurut data tersebut, kebutuhan air yang ada di SHB paling banyak 44.218 liter dan rata-rata air yang dapat ditampung mencapai 120.054 liter. Kapasitas air yang dibutuhkan lebih sedikit daripada air yang dapat ditampung, sehingga penampungan air dapat dibuat dengan minimal 44.218 liter untuk satu bulan. Penempatan PAH berada berada di celah antara gedung sekolah bagian belakang dan tembok pembatas yang memiliki panjang $7,7 \mathrm{~m} \times 2,5 \mathrm{~m}$ dengan luas $19,25 \mathrm{~m}^{2}$. Area tersebut dapat dibangun penampung air dengan tinggi 3 meter sehingga dapat menampung $57,75 \mathrm{~m}^{3}$ (57.750 liter). Kapasitas tersebut sudah cukup untuk memenuhi kebutuhan air yang ada di sekolah selama 1 bulan.

\subsubsection{Tanah}

Selain memiliki kandungan air yang kurang, sekolah ini memiliki kondisi tanah yang berkapur sehingga zat organik tanah menjadi kurang. Dalam mengatasi kondisi tanah berkapur dapat diatasi dengan penambahan biomassa yaitu serasah daun jati (Yuliani, 2016). Hal itu untuk menjaga bahan organik tanah sehingga dapat digunakan untuk nutrisi tanaman. Penambahan daun jati dapat dilakukan karena area sekolah banyak terdapat pohon jati yang menggugurkan daunya. Penambahan pupuk juga dapat meningkatkan unsur hara tanah. Selain itu, juga dapat menggunakan planterbox yang dibuat dengan cara menggali tanah yang akan digunakan untuk menanam sedalam 0,5-1,5 m dibawah permukaan tanah. Kondisi tanah yang tidak sesuai juga dapat diatasi menggunakan teknologi hidroponik agar tanaman bisa hidup. (Mulasari, 2019). Selain itu, dapat menggunakan vertical garden dalam mengatasi kondisi tanah yang berkapur dan banyaknya perkerasan yang digunakan.

\subsubsection{Vegetasi}

Sekolah ini memiliki vegetasi yang kurang dan menggunakan banyak perkerasan sehingga membuat suasana menjadi panas. Selain itu, kondisi pekarangan yang luas dapat dimanfaatkan sebagai Ruang Terbuka Hijau (RTH) untuk memunculkan suasana yang hijau dan enak dipandang. Oleh karena itu diperlukan penambahan vegetasi yang memiliki tajuk lebar, memiliki nilai estetik dan dapat tumbuh di tanah berkapur. Tajuk yang lebar berguna untuk menaungi pekarangan sekolah agar tidak terlalu panas. pemilihan tanaman dengan nilai estetik dimaksudkan untuk memperindah kondisi pekarangan sekolah dan pemilihan tanaman yang dapat tumbuh di kapur dipilih sesuai dengan kondisi tanah yang berkapur sehingga tidak mudah mati

\subsubsection{Adiwiyata}

Sekolah ini juga dapat digunakan sebagai sekolah adiwiyata dalam mendukung adanya RTH dan taman edukasi. Sekolah adiwiyata bertujuan untuk mewujudkan masyarakat sekolah yang peduli dan berbudaya lingkungan. Selain itu, hanya ada SMPN 1 Mengwi di Kab. Badung yang menjadi sekolah adiwiyata, sehingga SHB berpeluang untuk menjadi sekolah adiwiyata. Adiwiyata adalah sekolah yang baik dan ideal sebagai tempat memperoleh segala ilmu pengetahuan dan berbagai norma serta etika yang dapat menjadi dasar manusia menuju terciptanya kesejahteraan hidup dan cita-cita pembangunan berkelanjutan (Peraturan Menteri Lingkungan Hidup Republik Indonesia (Permen LH) No 2 Tahun 2009). Dalam pelaksanaanya, program ini mengacu pada Permen LH No. 13 Th. 2013 Tentang Pedoman Pelaksanaan Program Adiwiyata. Komponen program menurut peraturan tersebut terdiri dari: 1) Kebijakan berwawasan lingkungan, 2) Pelaksanaan kurikulum berbasis lingkungan, 3) Kegiatan lingkungan berbasis partisipatif, 4) Pengelolaan sarana pendukung ramah lingkungan. Akan tetapi, komponen yang dipakai hanya pada poin ke 3 dan ke 4 karena kurikulum sekolah sudah cukup padat dan sumber daya manusia yang belum memenuhi. Sekolah ini dapat melakukan kegiatan lingkungan berbasis partisipatif, Seperti: membuang sampah pada tempatnya, mengurangi pemakaian plastik sekali pakai, mendaur ulang bahan yang masih bisa dipakai, merawat tanaman dengan baik. Sedangkan, sarana pendukung yang sesuai dengan komponen adiwiyata yaitu penyediaan tempat sampah terpisah, ruang terbuka hijau, tanaman obat keluarga, biopori (sumur resapan) dan kolam ikan.

\subsection{Perencanaan}

\subsubsection{Konsep Dasar}

Perancangan yang dipakai pada SHB jimbaran ini menggunakan taman edukasi dengan konsep Adiwiyata. Konsep ini diharapkan dapat menjadikan taman sebagai sarana edukasi dan meningkatkan 
kepedulian untuk cinta lingkungan. Taman edukasi menggunakan pedoman menurut Mandagi (2013) dan konsep adiwiyata berpedoman pada Permen LH No 5 Tahun 2013 tentang Pedoman Pelaksanaan Program Adiwiyata. Hadirnya taman edukasi diharapkan dapat mengoptimalkan lahan di sekolah sekaligus sebagai fasilitas pendukung dalam proses edukasi dan meningkatkan kepedulian siswa dalam menjaga lingkungan.

4.4.2 Konsep Pengembangan

4.4.2.1 Konsep Ruang

Konsep ruang ini menerapkan green architecture yaitu pendekatan arsitektur dengan meminimalkan dampak negatif pada manusia dan lingkungannya (Sudarwani, 2012). Konsep ini mendukung konsep keberlanjutan dengan cara memaksimalkan potensi lahan dengan efisien dan penggunaan bahan yang ramah lingkungan.

\subsubsection{Konsep Vegetasi}

Konsep vegetasi ini menerapkan esthetic usefully yang mengutamakan keindahan dan fungsinya, tetapi tetap melihat syarat hidup tanaman diantaranya yaitu air, tanah, suhu dan penyinaran. Konsep ini membuat area tapak memiliki suasana yang lebih hijau, teduh dan dan menyehatkan.

\subsubsection{Konsep Sirkulasi}

Konsep sirkulasi yang digunakan memiliki pola cenderung linier yang bertujuan untuk mempermudah pengguna dalam mengakses lokasi tapak. Konsep sirkulasi ini dibagi menjadi 2 yaitu sirkulasi utama dan sirkulasi antar ruang. Sirkulasi utama adalah jalur sirkulasi untuk menuju area tapak sedangkan Sirkulasi antar ruang adalah jalur sirkulasi yang menghubungkan ruang yang satu dengan ruang yang lain.

\subsection{Perancangan}

\subsubsection{Rencana Tata Ruang, Aktivitas dan Fasilitas}

Konsep yang ada kemudian dirancang dengan membagi area menjadi area aktivitas, area fungsional dan area kebutuhan ruang. Area kegiatan termasuk area aktif dan pasif. Sedangkan, area fungsional termasuk area penerimaan, area penghubung dan area utama. Sesuai dengan kebutuhan ruang, area tersebut dibagi menjadi area terbangun sebanyak $22 \%$, area terbuka $63 \%$ dan area terbuka hijau $15 \%$ yang dilengkapi dengan fasilitas pergola dan tempat duduk untuk mendukung kegiatan pasif dan lapangan bermain untuk mendukung kegiatan aktif. Area hidroponik dan vertical garden juga disediakan untuk mendukung RTH. Penyediaan RTH sudah sesuai dengan Peraturan Daerah Kab. Badung No. 26 Th. 2013 Tentang Rencana Tata Ruang Wilayah Kabupaten Badung Tahun 2013 - 2033 yaitu dengan Koefisien Daerah Hijau sebanyak 10\%. Rencana tata ruang, aktivitas dan fasilitas dapat dilihat pada Tabel 1.

Tabel 1. Rencana tata ruang, aktivitas dan fasilitas

\begin{tabular}{cll}
\hline Ruang & \multicolumn{1}{c}{ Aktivitas } & \multicolumn{1}{c}{ Fasilitas } \\
\hline Penerimaan & - Antar jemput siswa (Pasif) & - Tempat tunggu siswa \\
Penghubung & - Sirkulasi menuju ruang utama (Aktif) & - Tanaman border \\
& - Bermain (Aktif) & - Tempat duduk santai \\
Utama & - Bersantai (Pasif) & \\
& - Olahraga (Aktif) & - Lapangan basket \\
& - Bersantai (Pasif) & - Tempat duduk bawah pohon \\
& - Membaca (Pasif) & - Pergola \\
& - Berenang (Aktif) & - Kolam renang \\
& - Berkebun (Aktif) & - Taman bermain \\
& - Belajar (Pasif) & - Wantilan \\
\hline
\end{tabular}

\subsubsection{Rencana Sirkulasi}

Perencanaan sirkulasi ini untuk mempermudah pengguna untuk menuju ke lokasi tapak atau menuju antar ruang dan fasilitas sesuai dengan konsep sirkulasi minimalis. Perencanaan sirkulasi penting diterapkan agar perpindahan pengguna lebih teratur dan tidak mengganggu pengguna lain (Gambar 3). 


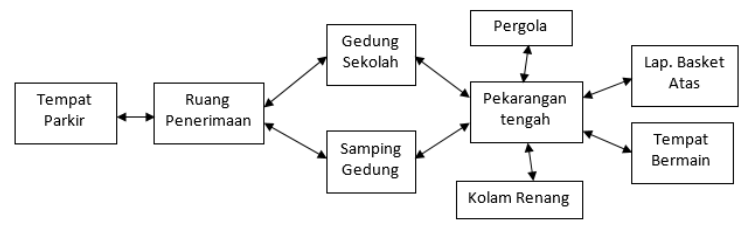

\subsubsection{Rencana Tata Hijau}

Gambar 3. Skema Keterkaitan Ruang

Perencanaan tata hijau ini merupakan penerapan konsep yang sudah dikembangkan kemudian pada rencana tata hijau ini dibagi menjadi 2 yaitu tata hijau estetik dan tata hijau usefully. Tata hijau estetik yaitu tanaman yang dipilih memiliki bentuk, warna dan visual yang bagus sehingga memperindah tapak sedangkan tata hijau usefully yaitu tanaman yang dipilih memiliki sifat yang kuat, tahan terhadap air, dan dapat menaungi. Penempatan vegetasi pada rencana tata hijau ini berbeda-beda. Berdasarkan hasil wawancara yang dilakukan kepada pihak sekolah, sering ada orang tidak dikenal meloncati dinding pembatas sehingga penempatan tanaman yang tinggi berada di pagar pembatas sedangkan vegetasi yang berjenis pohon diletakkan di area yang terbuka sehingga menjadi teduh. Dalam konsep ini tanaman eksisting juga tetap dipertahankan karena lebih mampu menyesuaikan diri dengan lingkungan. Selain pemilihan tanaman existing, rencana tata hijau ini menggunakan Tanaman Obat Keluarga (TOGA), tanaman upakara dan tanaman buah. Tanaman tersebut digunakan untuk meningkatkan pengetahuan mengenai jenis-jenis tanaman. Beberapa tanaman juga dapat digunakan sebagai tanaman pengusir nyamuk seperti tanaman serai dan lidah buaya. Pemilihan jenis tanaman yang digunakan dapat dilihat pada Tabel 2.

Tabel 2. Rencana Tata Hijau

\begin{tabular}{|c|c|c|c|c|}
\hline No & Jenis Tanaman & Nama Latin & Nama Lokal & Jumlah \\
\hline 1 & Buah & Muntingia calabura & Kersen & 2 \\
\hline 2 & Buah & Psidium guajava & Jambu biji & 3 \\
\hline 3 & Hias & Acalypha siamensis & Acalypha siamensis & 306 \\
\hline 4 & Hias & Aerva sanguinolenta & Bayam merah & 90 \\
\hline 5 & Hias & Arachis pintoi & Arachis pintoi & 2742 \\
\hline 6 & Hias & Canna indica & Bunga tasbih & 84 \\
\hline 7 & Hias & Cordyline fruticosa & Andong & 67 \\
\hline 8 & Hias & Crinum asiaticum & Crinum asiaticum & 178 \\
\hline 9 & Hias & Duranta erecta aurea & Duranta & 170 \\
\hline 10 & Hias & Heliconia psittacorum & Heliconia & 16 \\
\hline 11 & Hias & Ixora coccinea & Soka & 26 \\
\hline 12 & Hias & Jasminum sambac & Melati & 70 \\
\hline 13 & Hias & Pandanus pygmaeus & Pandan kuning & 75 \\
\hline 14 & Hias & Raphis excelsa & Palem waregu & 80 \\
\hline 15 & Hias & Sansevieria trifasciata & Sansivera & 13 \\
\hline 16 & Hias & Syzygium paniculatum & Pucuk merah & 40 \\
\hline 17 & Hias & Tradescantia spathacea & Adam hawa & 49 \\
\hline 18 & Pohon & Mangifera indica & Mangga & 2 \\
\hline 19 & Pohon & Polyalthia longifolia & Glodokan tiang & 6 \\
\hline 20 & Pohon & Tabebuia rosea & Tabebuya & 6 \\
\hline 21 & Pohon & Terminalia mantaly & Ketapang kencana & 4 \\
\hline 22 & Pohon & Thuja orientalis & Cemara kipas & 6 \\
\hline 23 & Pohon & Wodyetia bifurcate & Palem ekor tupai & 5 \\
\hline 24 & TOGA & Aloe vera. & Lidah buaya & 174 \\
\hline 25 & TOGA & Curcuma xanthorrhiza & Temulawak & 133 \\
\hline 26 & TOGA & Cymbopogon nardus & Serai wangi & 81 \\
\hline 27 & TOGA & Piper bettle & Sirih & 98 \\
\hline 28 & Upakara & Hibiscus rosa-sinensis & Bunga sepatu & 76 \\
\hline 29 & Upakara & Plumeria alba & Kamboja putih & 6 \\
\hline
\end{tabular}

Sumber: Data Lapangan dan Dokumen Pribadi

\subsection{Block Plan}

Block plan adalah gambar dua dimensi yang menunjukkan detail dari rencana awal pada sebuah tapak. Biasanya block plan merupakan gabungan dari tata ruang, tata hijau dan sirkulasi dalam satu gambar. Selanjutnya gambar block plan dapat dilihat pada Gambar 3. 


\subsection{Gambar Desain}

Konsep desain yang digunakan menggunakan konsep adiwiyata dengan memadukan edukasi dan peduli terhadap lingkungan. Selain itu, konsep ini juga bertujuan untuk mengetahui bentuk desain dari beberapa fasilitas yang disediakan untuk membantu dalam penerapan atau pembangunan fasilitas tersebut. Selanjutnya hasil akhir yang didapat pada penelitian ini berupa site plan yang dapat dilihat pada Gambar 4.

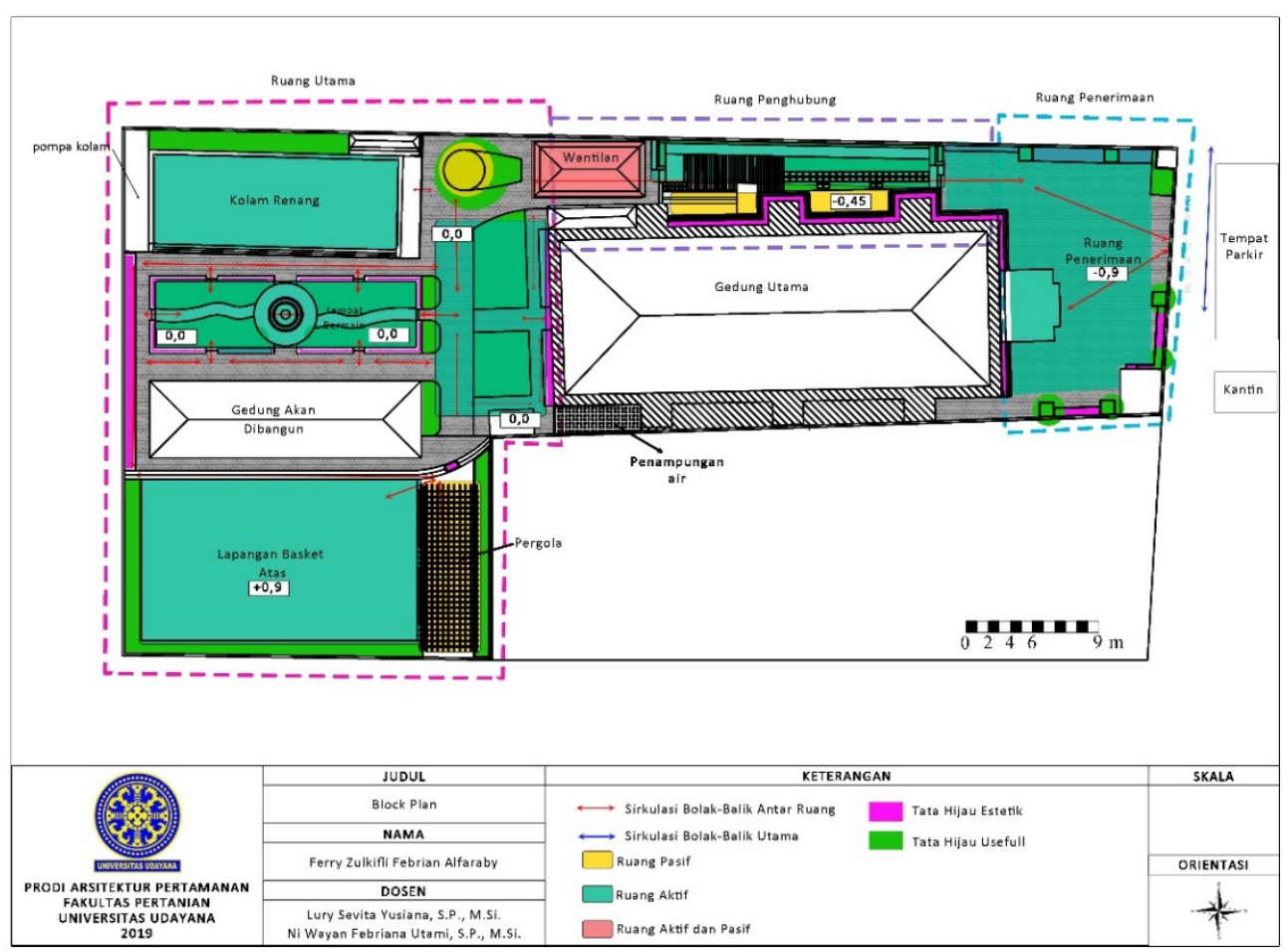

Gambar 4. Block Plan

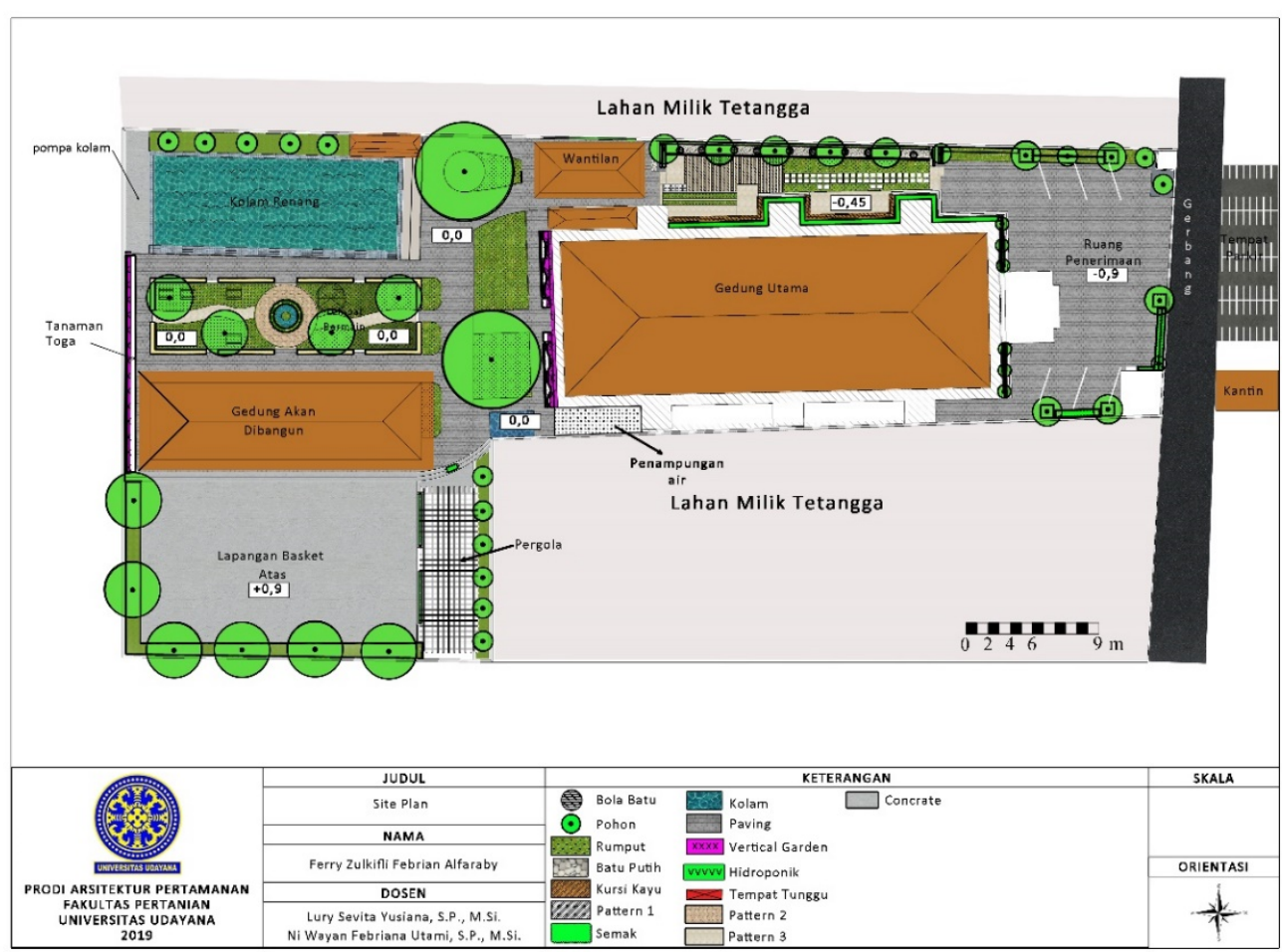

Gambar 5. Site Plan 


\subsubsection{Desain Pergola}

Pergola ini terletak di sebelah utara lapangan basket dengan ukuran panjang $15 \mathrm{~m}$, lebar $5 \mathrm{~m}$ dan tinggi $3 \mathrm{~m}$. Pergola ini memiliki desain yang simpel dengan menggunakan material dari alam seperti kayu dan batuan yang dapat terlihat dari material meja dan kerangka pergola (Gambar 5). Bagian atas pergola ini menggunakan tanaman buah-buahan sebagai penutup agar pergola tidak panas. Hal tersebut memunculkan kesan alami dan dapat digunakan untuk sarana edukasi dalam mengenalkan tanaman buah-buahan. Di bagian dalam pergola terdapat tempat duduk yang dapat digunakan untuk tempat bersosialisasi siswa baik untuk mengobrol, makan atau belajar. Pergola juga memiliki fungsi lain yaitu untuk tempat menonton basket atau acara yang ada di lapangan basket sehingga tidak terlalu panas.
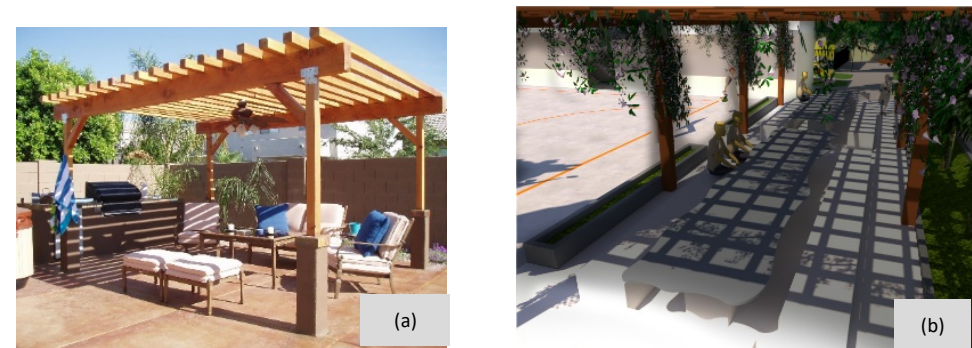

Gambar 6. (a). Ilustrasi Pergola dan (b). Desain Pergola

\subsubsection{Desain Tempat Duduk}

Desain tempat duduk yang digunakan terdapat 2 bagian yaitu untuk anak PAUD yang berada dibagian barat gedung sekolah diantara dinding yang menjorok ke arah barat dan untuk anak SD berada di bawah pohon mangga. Lokasi ini dipilih karena merupakan saran dari kepala sekolah untuk memanfaatkan area tersebut sebagai tempat sosialisasi. Tempat duduk yang digunakan menggunakan tinggi $40 \mathrm{~cm}$ dan lebar $40 \mathrm{~cm}$ sehingga tidak terlalu tinggi untuk siswa PAUD dan SD. Hal itu disesuaikan dengan tinggi kaki pengguna sehingga nyaman untuk dipakai. Detail desain tempat duduk dapat dilihat pada gambar 6 .
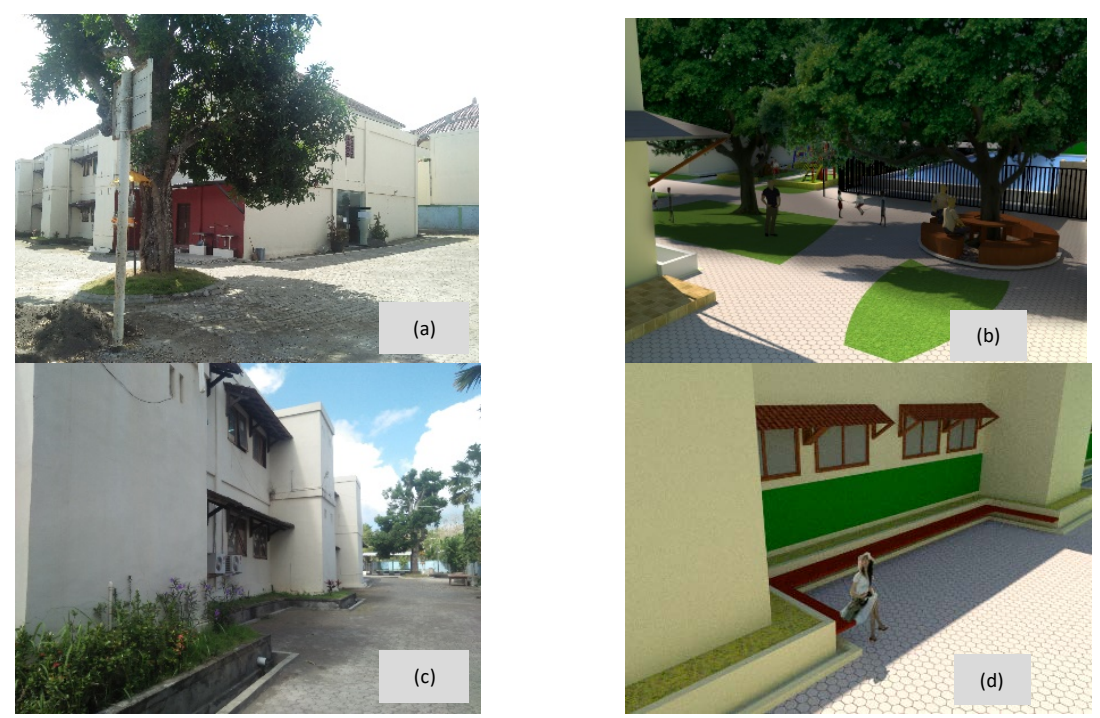

Gambar 7. (a) Lokasi Tempat Duduk Bawah Pohon, (b) Ilustrasi Tempat Duduk Bawah Pohon, (c) Lokasi Tempat Duduk Sebelah Gedung dan (d) Ilustrasi Tempat Duduk Sebelah Gedung

\subsubsection{Desain Vertical garden dan Hidroponik}

Hidroponik dan vertical garden terbuat dari pemanfaatan bahan-bahan daur ulang. Hal itu sejalan dengan Peraturan Gubernur Bali No 97 Tahun 2018 Tentang Pembatasan Timbulan Sampah Plastik Sekali Pakai. Peraturan tersebut diharapkan dapat membuat masyarakat lebih sadar mengenai dampak yang ditimbulkan oleh sampah plastik sekali pakai. Selain itu, bagi siswa dapat meningkatkan kemampuannya 
seninya karena barang daur ulang dapat dihias sesuai keinginan. Vertical garden dan hidroponik ditanami dengan sayur-sayuran seperti sawi, bayam, tomat, terong, kangkung dan cabai. Vertical garden dapat dibuat menggunakan bahan-bahan seperti botol bekas dan ember bekas. Sedangkan pada hidroponik dapat dibuat menggunakan pipa paralon yang dilubangi untuk tempat menanam. Metode penanaman vertical garden dilakukan secara vertikal atau dari atas ke bawah secara sejajar maupun digantung. Sedangkan metode dalam hidroponik menggunakan media berupa air yang terus mengalir tanpa terbuang karena berputar secara terus sehingga tidak memerlukan tanah. Penempatannya terletak di daerah selatan taman bermain karena disana potensial dengan area yang cukup luas dan kurangnya vegetasi. Penempatan vertical garden dapat diletakkan pada dinding luar gedung sekolah atau pada tembok pembatas area (Gambar 7).
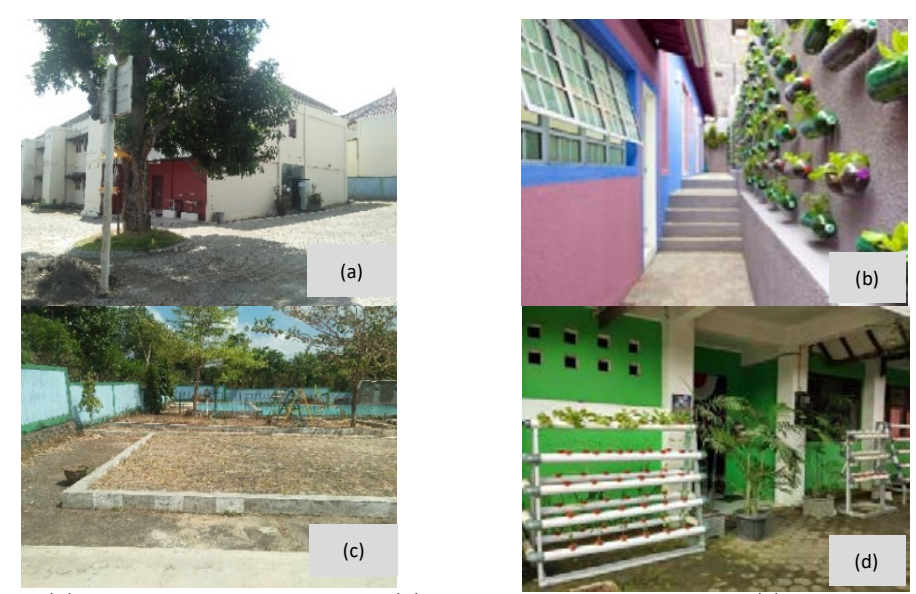

Gambar 8. (a) Lokasi Vertical Garden, (b) Ilustrasi Vertical Garden, (c) Lokasi Hidroponik, dan (d). llustrasi Hidroponik

\subsubsection{Penerapan Green architecture}

Menurut Sudarwani (2012), konsep Green architecture dapat diterapkan pada pekarangan SHB yaitu dengan memiliki konsep sustainable, konsep future healthy, konsep climate supportly dan esthetic usefully. Konsep sustainable bertujuan agar perancangan yang dilakukan dapat bertahan dalam jangka panjang dan tidak merusak lingkungan. Perancangan ini memaksimalkan sinar matahari sebagai pencahayaan alami pada pekarangan sekolah dan pergola (Gambar 8a). Pemanfaatan air hujan sebagai sumber air untuk keperluan domestik. Pemanfaatan air dilakukan dengan membuat tempat penampungan air hujan. Konsep future healthly dapat dilihat dari adanya tanaman rindang di pekarangan sekolah yang membuat iklim udara sejuk dan sehat bagi penggunanya (Gambar 8b). Sirkulasi yang ada dipekarangan juga sangat mudah dilalui dengan berjalan kaki (Gambar 8c). Hal tersebut dapat membiasakan pengguna berjalan kaki disamping banyaknya yang menggunakan kendaraan bermotor atau sarana lain untuk berpergian.

Konsep climate supportly dapat diterapkan dengan mengurangi penggunaan perkerasan.Adanya ruang terbuka hijau dapat sebagai penyejuk udara dan resapan air. Konsep esthetic usefully dapat meningkatkan keindahan agar menyatu dengan alam dan dapat digunakan sebagai proses pendingin ruangan alami karena sinar matahari tidak diserap beton secara langsung. Konsep ini dapat dilihat dengan penggunaan vertical garden dan penggunaan pohon rindang yang dapat membuat suasana teduh (Gambar 8d). 


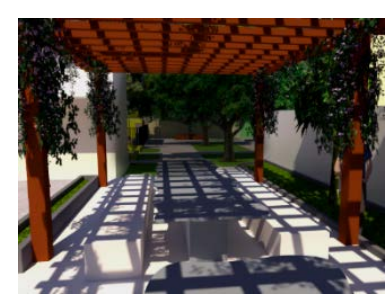

a. Pencahayaan alami pada pergola

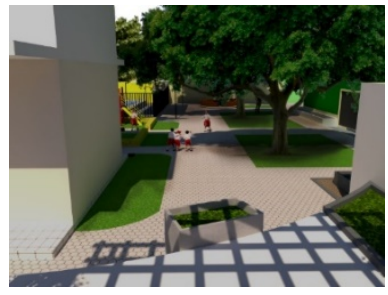

c. Sirkulasi pejalan kaki

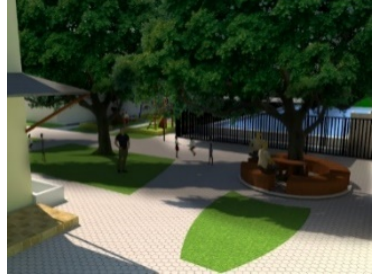

b. Pohon yang rindang

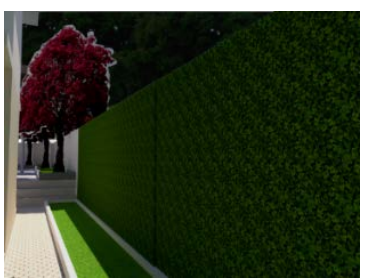

d. Vertical garden

Gambar 9. Penekanan Green architecture

\section{Simpulan dan Saran}

\subsection{Simpulan}

Perancangan taman edukasi SHB jimbaran dapat dipakai sebagai sarana peningkatan kesadaran lingkungan siswa sehingga dapat menekan kerusakan lingkungan yang saat ini banyak terjadi. Selain itu, juga dapat meningkatkan kenyamanan siswa dengan banyaknya pohon teduh yang ada di pekarangan sekolah sebagai RTH. Konsep yang diterapkan pada taman berbasis pembelajaran ini memadukan konsep edukasi dan peningkatan kesadaran siswa dalam menjaga lingkungan.

Perancangan ini juga mengatasi beberapa kendala dan mengoptimalkan potensi yang ada di sekolah, diantaranya penambahan fasilitas berupa pergola, taman bermain anak, tempat duduk santai, wantilan, vertical garden dan hidroponik. Penggunaan tempat Penampungan Air Hujan (PAH) sebagai energi alternatif untuk mengatasi sulitnya dalam mendapatkan air. Penggunaan metode cut and fill untuk mengurangi kondisi topografi yang miring. Penggunaan planter box untuk mengatasi tanah berkapur sebagai tempat untuk menanam tanaman. Meningkatkan jumlah vegetasi untuk membuat suasana yang ada di sekolah menjadi lebih teduh dan tidak panas.

Taman berbasis edukasi itu dapat dilihat dari penggunaan elemen fasilitas yang sifatnya alami, berkebun menggunakan hidroponik dan vertical garden, pergola yang dapat digunakan pembelajaran outdoor dan pengetahuan mengenai jenis tanaman yang ada di pekarangan sekolah. Selain itu, dikenalkan juga berbagai jenis tanaman, cara bercocok tanam dan cara dalam menjaga lingkungan. Peningkatan kesadaran menjaga lingkungan dapat dilakukan dengan pengelolaan daur ulang limbah plastik menjadi barang yang bermanfaat misalnya dalam bentuk vertical garden dan hidroponik sehingga siswa dapat belajar dan kemudian diharapkan dapat menerapkannya di rumah masing-masing.

\subsection{Saran}

Perlu adanya penelitian lanjutan mengenai kondisi tanah dan hidrologi pada SHB dan implementasi adiwiyata pada kurikulum sehingga mendukung keberadaan taman berbasis pembelajaran di Sekolah Harapan Bunda Jimbaran.

\section{Daftar Pustaka}

Awwalin, N. 2016. Menghitung Kebutuhan Air Bersih Pada Proyek Perumahan Jember New City (JNC).

Bupati Badung. 2013. Peraturan Daerah Kabupaten Badung No. 26 Tahun 2013 tentang Rencana Tata Ruang Wilayah Kabupaten Badung Tahun 2013 - 2033.

Dinas Cipta Karya. 2014. Dokumen Rencana Terpadu Program Investasi Infrastruktur Jangka Menengah (RPI2JM) Bidang Cipta Karya Kabupaten Badung. http://sippa.ciptakarya.pu.go.id/sippa_online/ 
ws_file/dokumen/rpi2jm/DOCRPIJM_1504704048Bab4-Profil_KabKota_bdg.pdf (diakses pada Mei 2018).

Ginanjar, G. G. 2008. Perancangan Lanskap Agrowisata Ikan Hias Air Tawar Di Balai Pengembangan Benih Ikan Ciherang Kabupaten Cianjur Jawa Barat. https://repository.ipb.ac.id/jspui/bitstream/ 123456789/1901/4/A08ggg.pdf (diakses pada Mei 2018).

Gubernur Bali. 2018. Peraturan Gubernur Bali Nomor 97 Tahun 2018 Tentang Pembatasan Timbulan Sampah Plastik Sekali Pakai.

Mandagi, A. U. G. 2013. Perancangan Taman Edukasi Lingkungan untuk Anak-anak di Situ Cikaret, Kecamatan Cibinong, Kabupaten Bogor. https://repository.ipb.ac.id/jspuil/bitstream/ 123456789/66082/1/A13aug.pdf (diakses pada Mei 2018).

Menteri Lingkungan Hidup Republik Indonesia. 2009. Peraturan Menteri Lingkungan Hidup Nomor 02 Tahun 2009 Tentang Pedoman Pelaksanaan Program Adiwiyata. https://doi.org/10.1017/CBO978 1107415324.004

Menteri Lingkungan Hidup Republik Indonesia. 2013. Peraturan Menteri Lingkungan Hidup Nomor 05 Tahun 2013 Tentang Pedoman Pelaksanaan Program Adiwiyata.

Mulasari, S. A. 2019. Penerapan Teknologi Tepat Guna (Penanam Hidroponik Menggunakan Media Tanam) Bagi Masyarakat Sosrowijayan Yogyakarta. Jurnal Pemberdayaan: Publikasi Hasil Pengabdian Kepada Masyarakat 2(3):425-430. https://doi.org/10.12928/jp.v2i3.418

Mursitantyo, A., Suarbawa, K. N., \& Septiadhi, A. 2015. Analisis Efek Tapak Lokal Dari Geologi Tanah Di Badung Selatan Dan Kota Denpasar Dengan Survei Mikrotremor (Studi Kasus Gempa Bumi Nusadua, 13 Oktober 2011). 1-10. Retrieved from https://ojs.unud.ac.id//index.php/ buletinfisika/article/view/30588 (diakses pada Mei 2018).

Sudarwani, M. M. 2012. Penerapan Green architecture Dan Green Building Sebagai Upaya Pencapaian Sustainable Architecture. In jurnal.unpand.ac.id. http://jurnal.unpand.ac.id/index.php/dinsain/ article/view/90 (diakses pada Mei 2018).

Widiyawati, N. 2018. Prediksi Siswa SD Negeri Mojosari Mantup Lamongan Berdasarkan Hasil Lolos Seleksi Di SMP Negeri Menggunakan Metode Naive Bayes. Declaration of Alma-Ata 1978. http://eprints. umg.ac.id/614/ (diakses pada Mei 2018).

Yayasan Pendidikan Bhakti Persada Nusantara. 2016. Yayasan Harapan Bunda Jimbaran. http://www. harapanbundajimbaran.com/tentang-kami.html (diakses pada Mei 2018).

Yuliani, \& Rahayu, Y. S. 2016. Pemberian Serasah Daun Jati Dalam Meningkatkan Kadar Hara Dan Sifat Fisika Tanah Pada Tanah Kapur. Prosiding Seminar Nasional Biologi 2016. Retrieved from https://www.researchgate.net/profile/Yuni_Rahayu/publication/318298897_PEMBERIAN_SERESAH_ DAUN_JATI_DALAM_MENINGKATKAN_KADAR_HARA_DAN_SIFAT_FISIKA_TANAH_PADA_TAN AH_KAPUR/links/59610b4c0f7e9b8194401683/PEMBERIAN-SERESAH-DAUN-JATI-DALAMMENINGKATKAN-KADAR-HA (diakses pada Mei 2018). 